\title{
MATERNAL AND PERINATAL OUTCOME IN ADVANCED MATERNAL AGE: A HOSPITAL BASED PROSPECTIVE STUDY
}

\author{
Sonika Gupta ${ }^{1}$, Deepak Kumar², Surinder Kumar³, Dinesh Kumar ${ }^{4}$ \\ ${ }^{1}$ Senior Resident, Department of Obstetrics and Gynaecology, SMGSH, GMC, Jammu. \\ ${ }^{2}$ Senior Resident, Department of Paediatrics, SMGSH, GMC, Jammu. \\ 3Professor, Department of Obstetrics and Gynaecology, SMGSH, GMC, Jammu. \\ ${ }_{4}^{4}$ Senior Resident, Department of Obstetrics and Gynaecology, SMGSH, GMC, Jammu.
}

\begin{abstract}
\section{BACKGROUND}

The term 'elderly parturient' was defined in 1958 by the Council of International Federation of Obstetrics as one aged 35 years or more at the first delivery. Rising trend of pregnancy in advanced maternal age has raised serious concerns amongst health providers because pregnancy in older age is considered to be more hazardous both from material and foetal prospective.

The aim of this study was to evaluate pre-existing medical disorders, antenatal complication, mode of delivery and perinatal outcome in advanced maternal age.
\end{abstract}

\section{MATERIAL AND METHODS}

This hospital based prospective study was conducted in SMGS Hospital, Jammu. It included 140 patients each in 2 groups with study group comprising of women with age $\geq 35$ years and control group comprising of women between 20-29 years of age. All the women who were fit in inclusion criteria underwent detailed history and examination and investigation. The study and control groups were compared according to the objectives.

\section{RESULTS}

Parity was significantly higher in the study group. Among antenatal complications, anaemia and hypertension were significantly higher in study group. There was no statistically significant difference in the incidence of malpresentation, preterm labour, antepartum haemorrhage and multiple pregnancies in the two groups. There was higher incidence of caesarean sections and instrumental deliveries in the study group. Among caesarean sections, rate of elective caesarean sections was significantly higher in the study group. No significant increase in the incidence of postpartum complications was seen in the study group. Patients of advanced maternal age were associated with adverse perinatal outcome in the form of higher incidence of babies with Apgar score $<7$ at 5 minutes and higher perinatal mortality.

\section{KEYWORDS}

Advanced Maternal Age, Maternal Outcome, Perinatal Outcome.

HOW TO CITE THIS ARTICLE: Gupta S, Kumar D, Kumar S, et al. Maternal and perinatal outcome in advanced maternal age: A hospital based prospective study. J. Evolution Med. Dent. Sci. 2016;5(82):6137-6140, DOI: 10.14260/jemds/2016/1386

\section{BACKGROUND}

The term 'elderly parturient' was defined in 1958 by the Council of International Federation of Obstetrics as one aged 35 years or more at the first delivery. ${ }^{1}$

Rising trend of pregnancy in advanced maternal age has raised serious concerns amongst health providers because pregnancy in older age is considered to be more hazardous both from material and foetal prospective. ${ }^{2}$

Chronic medical conditions are more prevalent among elderly group, particularly in the multiparous patients. There is increased incidence of pre-existing hypertension, diabetes mellitus, thyroid disorders, asthma, mental depression and many others. ${ }^{3}$

Antenatal complications more frequently encountered are preterm labour, antepartum haemorrhage, intrauterine

Financial or Other, Competing Interest: None.

Submission 03-09-2016, Peer Review 01-10-2016,

Acceptance 06-10-2016, Published 13-10-2016.

Corresponding Author:

Dr. Dinesh Kumar,

70/7, Model Town,

Gangyal, Jammu-180010.

E-mail: drdinesh1982@yahoo.com

DOI: $10.14260 /$ jemds/2016/1386 growth retardation, multiple pregnancy, malpresentations, pregnancy-induced hypertension, placenta abruption and placenta praevia.4,5 Mode of delivery significantly differs in advanced maternal age. Operative or instrumental delivery is more common. Caesarean section is five times more common in elderly. Induction of labour is more common in older women who are also more likely to be delivered by caesarean section or have operative vaginal delivery. Higher rates of labour abnormalities are found in the older women. ${ }^{6}$

There is increase in the perinatal mortality in advanced maternal age due to antenatal complications and lethal congenital anomalies. Perinatal mortality increases from $25 / 1000$ at $17-19$ years to $69 / 1000$ after age 39.7

However, many studies in the literature have yielded conflicting results and have found no difference in outcomes between younger and older women. ${ }^{6}$ No significant statistical differences regarding pre-maturity, low birth weight, hypertension, preterm labour, pre-eclampsia and operative vaginal delivery have been noticed between age $<35$ and $\geq 35.4$ This institutional study has evaluated maternal and perinatal outcome in advanced material age in our own setup where apart from the factors inherent to advanced maternal age, poor socioeconomic environment and practice of large family are still prevalent. 


\section{MATERIALS AND METHODS}

This was a hospital based study conducted on the patients reporting in the Department of Obstetrics and Gynaecology, SMGS Hospital, Jammu for a period of one year.

\section{Two Groups were made \\ Group A: Study Group \\ Group B: Control Group}

Study group included women $\geq 35$ years of age at the time of delivery while control group included women between 20 29 years of age delivering serially immediately after the women included in the study group.

\section{The Exclusion Criteria for Both the Groups Were}

1. Referred cases.

2. Deliveries before 20 completed weeks of gestation and of babies weighing $<500 \mathrm{~g}$.

3. Women giving birth to babies with congenital anomalies.

At the time of admission, a detailed history was taken. General physical, systemic and obstetric examinations were carried out. All investigations relevant to the particular case were done. Each patient was followed for seven days postpartum.

The study and the control groups were compared regarding:

\section{Pre-Existing Medical Disorders}

(a) Diabetes

(b) Hypertension

(c) Cardiac Disease

(d) Epilepsy

(e) Hypothyroidism

(f) Tuberculosis

(g) Bronchial Asthma and others Found During Study Period.

\section{Antenatal Complications}

(a) Anaemia

(b) Pregnancy Associated Hypertension

(c) Antepartum Haemorrhage

(d) Multiple Pregnancies

(e) Malpresentation.

(f) Preterm Labour.

\section{Onset of Labour}

(a) Spontaneous

(b) Induced.

\section{Mode of delivery \\ (a) Vaginal \\ (b) Caesarean \\ (c) Instrumental.}

\section{Postpartum Complications}

(a) Postpartum Haemorrhage

(b) Subinvolution of Uterus

(c) Puerperal Pyrexia

(d) DVT and Others. (c) NICU Admissions.

(d) Perinatal Mortality.

Results were expressed as mean ( \pm standard deviation). All results were analysed statistically with the help of Chi-square test, Fisher's exact test and Student's t-test wherever applicable. The difference was considered significant at $\mathrm{p}<0.05$.

\section{OBSERVATIONS AND ANALYSIS}

The present study included 140 patients in the study group (group A) and 140 patients in the control group (group B).

Average age of women in the study group was 35.93 $( \pm 1.42)$ years where as average age in the control group was $25.14( \pm 2.28)$ years.

Average gravidity in the study group was $2.94( \pm 1.45)$, as compared to $1.83( \pm 0.97)$ in the control group. The difference in gravidity between the two groups was statistically significant $(\mathrm{p}<0.0001)$.

Average parity in the study group was $1.42( \pm 1.15)$ while in the control group it was $0.65( \pm 0.81)$. The difference in the parity between the two groups was statistically significant $(\mathrm{p}<0.0001)$.

Pre-existing medical disorders in the study and control groups are shown in Table 1.

\begin{tabular}{|c|c|c|c|}
\hline $\begin{array}{c}\text { Medical } \\
\text { Disorders }\end{array}$ & $\begin{array}{c}\text { Study } \\
\text { Group n }\end{array}$ & $\begin{array}{c}\text { Control } \\
\text { Group n }\end{array}$ & \multirow{2}{*}{$\mathbf{p}$} \\
\hline Hypothyroidism & 2 & 0 & \multirow{2}{*}{$\mathrm{p}=0.12$} \\
\hline Heart Disease & 1 & 0 & \\
\hline Seizure Disorder & 1 & 0 & \\
\hline Renal Disease & 1 & 0 & \\
\hline Total & $\mathbf{5}$ & $\mathbf{0}$ & \\
\hline \multicolumn{3}{|c|}{ Table 1 } \\
\hline
\end{tabular}

The difference between the study and the control group in terms of these medical disorders was statistically insignificant $(\mathrm{p}=.12)$.

Antenatal complications in the study and control groups are shown in Table 2.

\begin{tabular}{|c|c|c|c|}
\hline Complication & $\begin{array}{c}\text { Study } \\
\text { Group n (\%) }\end{array}$ & $\begin{array}{c}\text { Control } \\
\text { Group n (\%) }\end{array}$ & p \\
\hline Anaemia & $37(26.42 \%)$ & $16(11.42 \%)$ & $\mathrm{P}=0.0014$ \\
\hline Hypertension & $35(25 \%)$ & $18(12.85 \%)$ & $\mathrm{P}=0.0009$ \\
\hline $\begin{array}{c}\text { Antepartum } \\
\text { Haemorrhage }\end{array}$ & $6(4.28 \%)$ & $1(0.71 \%)$ & $\mathrm{P}=0.12$ \\
\hline $\begin{array}{c}\text { Multiple } \\
\text { Pregnancy }\end{array}$ & $4(2.85 \%)$ & $2(1.42 \%)$ & $\mathrm{P}=0.68$ \\
\hline Malpresentation & $13(9.28 \%)$ & $7(5 \%)$ & $\mathrm{P}=0.24$ \\
\hline Preterm Labour & $14(10 \%)$ & $8(5.71 \%)$ & $\mathrm{P}=0.18$ \\
\hline \multicolumn{4}{|c|}{ Table 2 } \\
\hline
\end{tabular}

Among all these antenatal complications, the incidence of anaemia and hypertension was statistically significant in study group as compared to control group $(\mathrm{P}=0.0014$ and $\mathrm{P}=0.0009)$.

Onset of labour in the study and control groups is shown in Table 3.

\section{Perinatal Outcome \\ (a) Foetal Weight. \\ (b) Apgar Score.}




\begin{tabular}{|c|c|c|c|}
\hline $\begin{array}{c}\text { Labour } \\
\text { Onset }\end{array}$ & $\begin{array}{c}\text { Study Group } \\
\text { n (\%) }\end{array}$ & $\begin{array}{c}\text { Control Group } \\
\text { n (\%) }\end{array}$ & p \\
\hline Spontaneous & $97(77.6 \%)$ & $113(81.88 \%)$ & $\mathrm{p}=0.38$ \\
\hline Induced & $28(22.4 \%)$ & $25(18.12 \%)$ & \\
\hline \multicolumn{4}{|c|}{ Table 3 } \\
\hline
\end{tabular}

The difference between the study and the control group in terms of onset of labour was statistically insignificant $(\mathrm{p}=0.38)$.

Mode of delivery in the study and control groups is shown in Table no. 4.

\begin{tabular}{|c|c|c|c|}
\hline $\begin{array}{c}\text { Mode of } \\
\text { Delivery }\end{array}$ & $\begin{array}{c}\text { Study } \\
\text { Group n (\%) }\end{array}$ & $\begin{array}{c}\text { Control } \\
\text { Group n (\%) }\end{array}$ & p \\
\hline Vaginal & $94(67.14 \%)$ & $107(76.42 \%)$ & \multirow{2}{*}{$\mathrm{p}=0.03$} \\
\cline { 1 - 3 } Caesarean & $41(29.28 \%)$ & $33(23.57 \%)$ & 0 \\
\hline Instrumental & $5(3.57 \%)$ & \multicolumn{3}{|c|}{ Table 4 } \\
\cline { 1 - 2 } & \multicolumn{3}{|c|}{} \\
\hline
\end{tabular}

The difference between the study and the control group in terms of mode of delivery was statistically significant $(p=0.03)$.

The incidence of elective caesarean section was quite high in the study group. In the study group, out of 41 caesarean sections, $15(36.58 \%)$ were elective sections whereas only 2 caesarean were elective out of 33 in the control group. The differences between the two groups were highly significant $(\mathrm{p}=0.004)$.

Postpartum complications in the study and control groups are shown in Table 5.

\begin{tabular}{|c|c|c|c|}
\hline Complication & $\begin{array}{c}\text { Study } \\
\text { Group n (\%) }\end{array}$ & $\begin{array}{c}\text { Control } \\
\text { Group n (\%) }\end{array}$ & p \\
\hline $\begin{array}{c}\text { Postpartum } \\
\text { Haemorrhage }\end{array}$ & $4(2.85 \%)$ & $2(1.42 \%)$ & \\
\cline { 1 - 2 } Retained Placenta & $3(2.14 \%)$ & $1(0.71 \%)$ & \multirow{2}{*}{$\mathrm{p}=0.037$} \\
\cline { 1 - 2 } Ruptured Uterus & $1(0.71 \%)$ & 0 & \\
\cline { 1 - 3 } Vulval Haematoma & 0 & $1(0.71 \%)$ & \\
\cline { 1 - 3 } Total & $\mathbf{8 ( 5 . 7 1 \% )}$ & $\mathbf{4 ( 2 . 8 5 \% )}$ & \\
\hline \multicolumn{3}{|c|}{ Table 5 } \\
\hline
\end{tabular}

Average birth weight of babies in study group was 2.68 $( \pm 0.58) \mathrm{kg}$ as compared to $2.66( \pm 0.35) \mathrm{kg}$ in the control group. The difference in weight between the two groups was statistically insignificant $(\mathrm{p}=0.72)$.

Foetal and neonatal outcomes in the study and control groups are shown in Table no. 6.

\begin{tabular}{|c|c|c|c|}
\hline Outcome & $\begin{array}{c}\text { Study } \\
\text { Group n (\%) }\end{array}$ & $\begin{array}{c}\text { Control } \\
\text { Group n (\%) }\end{array}$ & p \\
\hline $\begin{array}{c}\text { Apgar Score <7 at 5 } \\
\text { Minutes }\end{array}$ & $20(13.88 \%)$ & $4(2.81 \%)$ & $\mathrm{P}=0.007$ \\
\hline NICU Admissions & $15(10.41 \%)$ & $10(7.04 \%)$ & $\mathrm{P}=0.32$ \\
\hline Perinatal Mortality & $17(11.80 \%)$ & $2(1.41 \%)$ & $\mathrm{P}=0.001$ \\
\hline \multicolumn{4}{|c|}{ Table 6 } \\
\hline
\end{tabular}

Among foetal and neonatal outcomes, the incidence of Apgar score $<7$ at 5 minutes and perinatal mortality was statistically significant in study group as compared to control group ( $\mathrm{P}=0.007$ and $\mathrm{P}=0.001)$.

\section{DISCUSSION}

The present study included 140 women in the study group ( $\geq 35$ years) and 140 women in control group (20-29 years). There was significantly lower number of nulliparas in the study group, $27(19.28 \%)$ as compared to $73(52.14 \%)$ in the control group. This is in accordance to study by Jolly $\mathrm{M}$ et al. ${ }^{8}$

Mean gravidity and mean parity, $2.94( \pm 1.45)$ and 1.42 $( \pm 1.15)$ in the study group were significantly higher than 1.83 $( \pm 0.97)$ and $0.65( \pm 0.81)$ respectively observed in the control group. This is similar to study by Sahu TM et $\mathrm{al}^{2}$ who found the mean parity in the study group ( $\geq 35$ years) to be 1.69 and in the control group (20-29 years) to be 0.73 . The high parity and gravidity in our study probably reflects the increased family size in our setup.

In our study, there was statistically no difference between the study and the control groups as far as pre-existing medical disorders were concerned. This is in contrast to study by Sahu $\mathrm{TM}$ et $\mathrm{al}^{2}$ who reported a significantly higher incidence of diabetes in the study group (4.1\%) as compared to controls $(0.7 \%)$.

Anaemia was seen in $26.42 \%$ patients in the study group and $11.42 \%$ patients in the control group and the difference was statistically significant $(p=0.0014)$ This is similar to studies by Jolly $\mathrm{M}$ et $\mathrm{al}^{8}$ and Kane $\mathrm{SH}$ et $\mathrm{al}^{9}$ who observed an increased incidence of anaemia with increasing maternal age. The incidence of hypertension in pregnancy was significantly higher in the study group, $25 \%$ as compared to $12.85 \%$ in the control group. This is in accordance to studies by Amarin VN et $\mathrm{al}^{10}$ Ustun $\mathrm{Y}$ et $\mathrm{al}^{11}$ and Sahu TM et $\mathrm{al}^{2}$ who found higher incidence of hypertension in elderly gravidae. This increase is likely related to the underlying progressive vascular endothelial damage that occurs with ageing. ${ }^{12}$

Antepartum haemorrhage was reported in $4.28 \%$ of the women in the study group as compared to $0.71 \%$ in control group. Although number of women having antepartum haemorrhage was higher in study group, but the difference was statistically insignificant. This is similar to studies by Amarin VN et $\mathrm{al}^{10}$ and Sahu TM et $\mathrm{al}^{2}$ who also found an increased yet insignificant incidence of antepartum haemorrhage. There was no statistically significant difference in the incidence of multiple pregnancies in the two groups in our study. This is in contract to study by Amarin VN et al ${ }^{10}$ who found statistically significant difference of incidence of multiple pregnancies among two groups. In our study, there was higher incidence of malpresentation, 9.28\% in the study group as compared to $5 \%$ in the control group. The difference was statistically insignificant. This is similar to study by Sahu TM et al. ${ }^{2}$

In our study, the incidence of preterm labour was $10 \%$ in the study group as compared to $5.7 \%$ in the control group and the difference was statistically insignificant. This is in contrast to study by Sahu TM et al $^{2}$ who found significantly a higher incidence of preterm labour in the study groups. Labour was induced in $22.4 \%$ of the patients in the study group and $18.12 \%$ in the control group and the difference was statistically insignificant. This is in accordance to study by Luke B et $\mathrm{al}^{13}$ who found an increased incidence of induction of labour with increasing maternal age in primiparas.

In our study, there was statistically significant difference in the mode of deliveries between the two groups. Rates of caesarean sections and instrumental deliveries were higher in the study group. This is similar to study by Ustun Y et al ${ }^{11}$ who 
also found statistically significant difference in the mode of deliveries in the two groups. Among those delivered by caesarean section, our study found a significantly higher incidence of elective caesarean sections in the study group as compared to that in the control group. This is in accordance to studies by Edge VL et al ${ }^{6}$ and Jolly $\mathrm{M}$ et $\mathrm{al}^{8}$ who also found an increased incidence of elective caesarean in study group.

In our study, there was $100 \%$ increase in the postpartum complications in the study group (5.71\%) as compared to the control group $(2.85 \%)$ though the difference was statistically insignificant. Postpartum haemorrhage was twice as common in study group (2.85\%) as in the control group (1.42\%). This is similar to study by Amarin $\mathrm{VN}$ et al ${ }^{10}$ who also reported a higher incidence of post-partum haemorrhage in women aged $\geq 35$ years. Retained placenta was seen in $2.14 \%$ of patients in study group as compared to $0.71 \%$ in control group. This is similar to study by Edge VL et al ${ }^{6}$ who also found increased incidence of retained placenta in women aged $\geq 35$ years.

The average birth weight of babies was $2.68 \pm 0.58 \mathrm{~kg}$ and $2.66 \pm 0.36 \mathrm{~kg}$ in the study and control groups respectively and the difference was not statistically significant. Ustun $Y$ et al ${ }^{11}$ also did not find any significant difference in the birth weight of babies born to mothers $<35$ years and those born to mothers $\geq 35$ years of age. There was no difference in the proportion of low birth weight babies in the two groups. Amarin VN et al 10 also did not find any significant difference in the incidence of low birth weight babies in women aged $\geq 35$ years and in those aged less than 35 years.

In our study, the incidence of macrosomic babies was $3.47 \%$ in the study group as compared to $0.7 \%$ in the control group and the difference was statistically insignificant but Amarin VN et al ${ }^{10}$ found a significantly higher incidence of macrosomic babies in women aged $\geq 35$ years $(20.2 \%)$ as compared to that in $<35$ years of age.

Apgar score $<7$ at 5 minutes indicating foetal distress was observed in $13.88 \%$ of newborns in our study group as compared to $2.8 \%$ in the control group and the difference was statistically significant. This is similar to studies by Ustun Y et al ${ }^{11}$ and Sahu TM et al $^{2}$ who also found significantly higher incidence of newborns with 5-minute Apgar score $<7$ in women $\geq 35$ years of age.

There was no significant difference in the NICU (neonatal intensive care unit) admissions between the two groups. Ustun $Y$ et al ${ }^{11}$ also did not find any significant difference in the incidence of NICU admissions in newborns born to mothers $\geq 35$ years of age $(7.8 \%)$ as compared to those born to mothers $<35$ years of age. There was significantly high perinatal mortality in the study group, $11.80 \%$ as compared to $1.4 \%$ in the control group. This is similar to study by Kessler I et al ${ }^{14}$ and Edge VL et al ${ }^{14}$ who also found increased perinatal mortality in primiparas $\geq 35$ years of age.

\section{REFERENCES}

1. Kirz DS, Dorchester W, Freeman RK. Advanced maternal age: the mature gravida. Am J Obstet Gynecol 1985:152(1):7-12.

2. Sahu TM, Agarwal A, Das V. Advanced maternal age and obstetric outcome. J Obstet Gynecol India 2007;57(4):320-3.

3. Dildy GA, Jackson GM, Fowers GK, et al. Very advanced maternal age: pregnancy after age 45. Am J Obstet Gynecol 1996;175(3 Pt 1):668-74.

4. Goldman JC, Malone FD, Vidaver J, et al. Impact of maternal age on obstetric outcome. Obstet Gynecol 2005;105(5 Pt 1):983-90.

5. Gilbert WM, Nesbitt TS, Danielsen B. Childbearing beyond age 40: pregnancy outcome in 24,032 cases. Obstet Gynecol 1999;93(1):9-14.

6. Edge V, Laros RK. Pregnancy outcome in nulliparous women aged 35 or older. Am J Obstet Gynecol 1993;168(6 Pt 1):1881-5.

7. Naeye RL. Maternal age, obstetric complications and the outcome of pregnancy. Obstet Gynecol 1983;61(2):210-6.

8. Jolly M, Sebire N, Harris J, et al. The risks associated with pregnancy in women aged 35 years or older. Hum Reprod 2000;15(11):2433-7.

9. Kane SH. Advancing age and the primigravida. Obstet Gynecol 1967;29(3):409-14.

10. Amarin VN, Akasheh HF. Advanced maternal age and pregnancy outcome. EMHJ 2001;7(4-5):646-51.

11. Ustun Y, Engin-Ustun Y, Meydanli R, et al. Maternal and neonatal outcome in pregnancies at 35 and older age group. J Turkish German Gynecol Assoc 2005;6(1):46-8.

12. Bianco A, Stone J, Lynch L, et al. Pregnancy outcome at age 40 and older. Obstet Gynecol 1996;87(6):917-22.

13. Luke B, Brown MB. Contemporary risks of maternal morbidity and adverse outcomes with increasing maternal age and plurality. Fertil Steril 2007;88(2): 283-93.

14. Kessler L, Lancet M, Borenstein R, et al. The problem of the older primipara. Obstet Gynecol 1980;56(2):165-9. 